OPEN ACCESS

Edited by:

Yanyan Jiang,

Shandong University, China

Reviewed by:

Yuanzeng Min,

University of Science and Technology of China, China

Jiangwei Tian,

China Pharmaceutical

University, China

*Correspondence:

Tao Deng

dengtao@gzucm.edu.cn

Fang Liu

fangliu@gzucm.edu.cn

Specialty section:

This article was submitted to

Nanoscience,

a section of the journal

Frontiers in Chemistry

Received: 05 March 2020

Accepted: 06 May 2020

Published: 17 June 2020

Citation:

Wu Y, Zeng Q, Qi Z, Deng T and Liu F (2020) Recent Progresses in Cancer

Nanotherapeutics Design Using Artemisinins as Free Radical Precursors. Front. Chem. 8:472. doi: 10.3389/fchem.2020.00472

\section{Recent Progresses in Cancer Nanotherapeutics Design Using Artemisinins as Free Radical Precursors}

\author{
Yalan Wu ${ }^{1,2}$, Qingping Zeng ${ }^{2}$, Zhiwen $\mathrm{Qi}^{3}$, Tao Deng ${ }^{\text {** }}$ and Fang Liu ${ }^{1 *}$ \\ ${ }^{1}$ Institute of Tropical Medicine and Artemisinin Research Center, Guangzhou University of Chinese Medicine, Guangzhou, \\ China, ${ }^{2}$ Science and Technology Innovation Center, Guangzhou University of Chinese Medicine, Guangzhou, China, \\ ${ }^{3}$ Institute of Chemical Industry of Forest Products, Chinese Academy of Forestry (CAF), Nanjing, China
}

Artemisinin and its derivatives (ARTs) are sort of important antimalarials, which exhibit a wide range of biological activities including anticancer effect. To solve the issues regarding poor solubility and limited bioavailability of ARTs, nanoformulation of ARTs has thus emerged as a promising strategy for cancer treatment. A common consideration on nanoARTs design lies on ARTs' delivery and controlled release, where ARTs are commonly regarded as hydrophobic drugs. Based on the mechanism that ARTs' activation relies on ferrous ions $\left(\mathrm{Fe}^{2+}\right)$ or $\mathrm{Fe}^{2+}$-bonded complexes, new designs to enhance ARTs' activation have thus attracted great interests for advanced cancer nanotherapy. Among these developments, the design of a nanoparticle that can accelerate ARTs' activation has become the major consideration, where ARTs have been regarded as radical precursors. This review mainly focused on the most recent developments of ARTs nanotherapeutics on the basis of advanced drug activation. The basic principles in those designs will be summarized, and a few excellent cases will be also discussed in detail.

Keywords: artemisinins, anticancer, nanomedicine, chemodynamic therapy, free radicals

\section{INTRODUCTION}

Artemisinin (ART) is derived from the extracts of Artemisia annua, a Chinese herbal plant, and it is well-established for the treatment of malaria. Up to date, several semi-synthetic derivatives of ART have been synthesized and clinically applied, including artesunate (AS), dihydroartemisinin (DHA), artemether (ARM), and arteether (ARE). Besides anti-malarial usage, the therapeutic effect of ARTs has also been extended to non-parasitic diseases, such as inflammatory disease and cancer (Krishna et al., 2008; Li, 2012). ARTs have been proved to be effective to treat a wide range of cancers both in vitro and in vivo (Wong et al., 2017). Although the anticancer mechanism of ARTs is not fully discovered yet, some investigations have pointed out that $\mathrm{Fe}^{2+}$ may be the natural catalyst in cells that mediates ARTs' activation. $\mathrm{Fe}^{2+}$-catalyzed opening of the endoperoxide bridge is through an Fenton-like reaction, which generates alkyl radicals and reactive oxygen species (ROS) that can subsequently react with susceptible protein targets (O'neill et al., 2010; Wang et al., 2015; Deng et al., 2020). Tumor cells often have elevated iron accumulation, which has been regarded as one of the leading reasons why ARTs can kill cancer cells selectively (Pfeifhofer-Obermair et al., 2018; Zhang et al., 2018). 
However, using ARTs for real cancer therapy has been limited by their poor solubility, low bioavailability, and extremely short half-life in vivo (De Vries and Dien, 1996; Dwivedi et al., 2015). Nanotechnology offers the possibilities to overcome those drawbacks, thus being extensively used in the delivery of drugs especially for those with difficulty in water solubility (Kalepu and Nekkanti, 2015; Patra et al., 2018). A general method for ARTs delivery is loading the drug molecules within a certain nanocarrier, which could be made from inorganic or organic substrates, or both of them (Wang et al., 2016b; Mangrio et al., 2017; Manjili et al., 2018; Xiao et al., 2020). Additional chemistry for achieving tumor targeting and controllable drug release is often considered during the design (Tran et al., 2016; Jabbarzadegan et al., 2017; Akbarian et al., 2020). Up to date, numerous nanosystems have been reported for ARTs delivery and controlled release, and those studies have been well-summarized in previous review articles (Chen et al., 2009; Aderibigbe, 2017; Charlie-Silva et al., 2018). Another much advanced strategy to improve the therapeutic effect of ARTs is the method of socalled chemodynamic therapy (CDT), which has been attracting interests for cancer treatment via localized Fenton reaction (Tang et al., 2019; Zhao et al., 2019). Therefore, the ways of the delivery and controlled release of active Fenton reagent such as $\mathrm{Fe}^{2+}$ to accelerate ARTs' activation are attracting the great attentions in the design of ART-CDT nanotherapeutics. The main target of those nanosystems is to cause free radical burst thus leading to cell toxicity, whereby ARTs are usually used as radical precursors. In the present review, we will focus on the recent progress mostly within the last 5 years in cancer nanotherapeutics design using ARTs as free radical precursors. The discussion will be divided into four parts according to the differences of technique aspects.

\section{ARTS NANOTHERAPEUTICS}

\section{Iron Oxide-Based ARTs Nanotherapeutics}

With the common sense that $\mathrm{Fe}^{2+}$ ions are the most active species that can activate ARTs, iron oxide-based inorganic and inorganic/organic hybrid nanoparticles have therefore been considered for ARTs' delivery and controlled activation. Most of these nanoparticles are made from the mixtures of $\mathrm{Fe}^{2+}$ and $\mathrm{Fe}^{3+}$, which are potentially able to release active $\mathrm{Fe}^{2+}$ in mild acidic environment of tumor tissues and acidic intracellular compartments. In addition, many oxide nanoparticles are paramagnetic and serve as excellent contrast reagents for magnetic resonance imaging (MRI), which offers the possibilities for the development of advanced theranostics (Bao et al., 2018). Up to now, several iron oxide-based ART nanotherapeutics have been reported and proved to be effective in vitro and in vivo in cancer therapies. For example, Chen et al. have reported a nanoparticle $\mathrm{Fe}_{3} \mathrm{O}_{4} @ \mathrm{C} / \mathrm{Ag} @ \mathrm{mSiO}_{2}$ with mesoporous properties, which can load with ART up to $484 \mathrm{mg} / \mathrm{g}$. This nanoparticle was internalized by cancer cells mainly through endocytosis pathways, $\mathrm{Fe}_{3} \mathrm{O}_{4}$ in acidic endo/lysosome was able to release catalytic $\mathrm{Fe}^{2+}$ that further activated the generation of radical species from ART. The authors found elevated apoptosis to HeLa cells treated with this nanoparticle compared with ART itself (Chen et al., 2014). By following this design, the same group has presented another $\mathrm{Fe}_{3} \mathrm{O}_{4}$-based nanosystem $\mathrm{Fe}_{3} \mathrm{O}_{4} @ \mathrm{C} @ \mathrm{MIL}$ $100(\mathrm{Fe})$, where dihydroartemisinin (DHA) was encapsulated as radical precursors. More interestingly, this system is able to increase the accumulation of DHA and $\mathrm{Fe}^{2+}$ within targeted cancer cells under the guidance of an external magnetic field. Much improved therapeutic effect has been found in vivo in this study (Wang et al., 2016a).

The cases above have revealed that targeting to the acidic endo/lysosome is a promising way to achieve $\mathrm{Fe}^{2+} / \mathrm{Fe}^{3+}$ release from iron oxide nanoparticles. By following these studies, several ARTs nanosystems have been reported most recently (Wang D. et al., 2017; Zhang et al., 2017; Pan et al., 2018; Guo et al., 2019; Li et al., 2019; Qin et al., 2019). Generally, nanoparticles are easy to be chemically modified with additional ligands to strengthen the functionalities. For instance, Zhang et al. (2016) reported a multi-functional nanoparticle, in which hyaluronic acid (HA) was grafted on the ART doped mesoporous $\mathrm{Fe}_{3} \mathrm{O}_{4}$ core structures. Controlled release of $\mathrm{Fe}^{2+}$ and ART is thus achievable since tumor cells are often enriched with hyaluronidases (Mcatee et al., 2014). Such an HA-gate method has also been applied in another report by the same research group (Zhang et al., 2017). In a recent report, an additional cancer cell-targeting and membrane-penetrating RGD peptide was integrated on a $\mathrm{Fe}_{3} \mathrm{O}_{4} @$ cisplatin/ART nanoparticle to form ART-loaded cRGDAFePt@NPs for cancer targeted co-delivery of cisplatin and ART, and controlled drug activation (Gao et al., 2018). The most recently reported iron oxide nanosystems for ARTs-based cancer therapeutics have been summarized and listed in Table 1. We do believe that this sort of design will be continually applied in the fabrication of advanced ARTs nanodrugs in the future.

\section{Iron-Containing Soft Matters for ARTs Delivery and Activation}

Polymeric soft matters including natural proteins, polysaccharides, and synthetic polymers have gained great attentions for the fabrication of nanotherapeutics. Numerous small molecular drugs have been provided as nanoformulations in clinic applications by using polymeric soft matters as drugs' nanocarriers (Malmsten, 2006; Liechty et al., 2010). Different to other small molecular drugs, a successful delivery system for ARTs-based cancer treatment requires not only effective drug release but also efficient peroxide bridge activation. Therefore, the soft matters that can serve as the carriers for both ARTs and the catalyst $\mathrm{Fe}^{2+} / \mathrm{Fe}^{3+}$ are much extensively studied.

Transferrin, a kind of iron containing proteins, has been used as nanocarriers to directly deliver ARTs for cancer therapy in several cases. One of the earliest reports presented a drug-protein complex by covalently conjugating an ART derivative with the carbohydrate chains of transferrin. In vivo evidence showed that linkage with transferrin can greatly enhance the therapeutic effect of ART on the mice implanted with human ovarian cancer cells, HO-8910 (Nakase et al., 2008). It has also been found that transferrin with ART tagged with lysine residues was less effective than those with ART tagged to the carbohydrate chains (Lai et al., 2005). Direct conjugation of ARTs to transferrin may lead to some drawbacks such as limited loading efficiency and 
TABLE 1 | Recent developments of iron oxide nanoparticle-based ARTs nanotherapeutics.

\begin{tabular}{|c|c|c|c|c|c|c|c|}
\hline & Nanotherapeutics & ARTs & DLC & Activator & Strategy & Evidence & References \\
\hline 1 & $\mathrm{Fe}_{3} \mathrm{O}_{4} @ \mathrm{C} / \mathrm{Ag} @ \mathrm{mSiO}_{2}$ & ART & $48.4 \%$ & $\mathrm{Fe}^{2+} / \mathrm{Fe}^{3+}$ & ART-CDT & in vitro & Chen et al., 2014 \\
\hline 2 & $\mathrm{Fe}_{3} \mathrm{O}_{4} @ \mathrm{C} @ \mathrm{MIL}-100(\mathrm{Fe})$ & $\mathrm{DHA}$ & $80.4 \%$ & $\mathrm{Fe}^{2+} / \mathrm{Fe}^{3+}$ & ART-CDT & in vitro/in vivo & Wang et al., 2016a \\
\hline 3 & $\begin{array}{l}\mathrm{Mn}_{3}\left[\mathrm{Co}(\mathrm{CN})_{6}\right]_{2} @ \mathrm{MIL}-100 \\
(\mathrm{Fe})\end{array}$ & AS & $53.1 \%$ & $\mathrm{Fe}^{2+} / \mathrm{Fe}^{3+}$ & ART-CDT & in vitro/in vivo & Wang D. et al., 2017 \\
\hline 4 & ART@HQZFNPs & ART & $23.0 \%$ & $\mathrm{Fe}^{2+} / \mathrm{Fe}^{3+}$ & ART-CDT & in vitro & Pan et al., 2018 \\
\hline 5 & $\begin{array}{l}\text { MNP-ART, MNP-DHA, } \\
\text { MNP-AS }\end{array}$ & $\begin{array}{l}\text { ART, DHA, } \\
\text { AS }\end{array}$ & $\begin{array}{l}15.3 \% \\
15.3 \% \\
15.7 \%\end{array}$ & $\mathrm{Fe}^{2+} / \mathrm{Fe}^{3+}$ & ART-CDT & in vitro & Guo et al., 2019 \\
\hline 6 & DHA-MLPs & $\mathrm{DHA}$ & $82.1 \%$ & $\mathrm{Fe}^{2+} / \mathrm{Fe}^{3+}$ & ART-CDT & in vitro/in vivo & Li et al., 2019 \\
\hline 7 & $\mathrm{Fe}_{3} \mathrm{O}_{4} @ \mathrm{SiO}_{2}-\mathrm{ART}-\mathrm{HNPa}$ & ART & $45.2 \%$ & $\mathrm{Fe}^{2+} / \mathrm{Fe}^{3+}$ & ART-CDT, PDT & in vitro & Qin et al., 2019 \\
\hline 8 & $\mathrm{~A}-\mathrm{TiO}_{2}-\mathrm{IONPS} / \mathrm{ART}$ & ART & $27.5 \%$ & $\mathrm{Fe}^{2+} / \mathrm{Fe}^{3+}$ & ART-CDT, PDT & in vitro/in vivo & Zhang et al., 2017 \\
\hline 9 & $\mathrm{HA}-\mathrm{mFe}_{3} \mathrm{O}_{4} / \mathrm{ART}$ & ART & $52.8 \%$ & $\mathrm{Fe}^{2+} / \mathrm{Fe}^{3+}$ & ART-CDT, AMF & in vitro/in vivo & Zhang et al., 2016 \\
\hline 10 & cRGD-AFePt@NPs & ART & $5.2 \%$ & $\mathrm{Fe}^{2+} / \mathrm{Fe}^{3+}$ & $\begin{array}{l}\text { ART-CDT } \\
\text { Cisplatin }\end{array}$ & in vitro & Gao et al., 2018 \\
\hline 11 & $\mathrm{Fe}_{3} \mathrm{O}_{4} @ \mathrm{MnSiO}_{3}-\mathrm{FA}$ & ART & $21.9 \%$ & $\begin{array}{l}\mathrm{Mn}^{2+} \\
\mathrm{Fe}^{2+} / \mathrm{Fe}^{3+}\end{array}$ & ART-CDT & in vitro/in vivo & Chen et al., 2015 \\
\hline 12 & $\begin{array}{l}\text { ART-MSP } \\
\text { loaded with ICG }\end{array}$ & ART & $22.5 \%$ & $\mathrm{Fe}^{2+} / \mathrm{Fe}^{3+}$ & ART-CDT, PTT & in vitro/in vivo & Ding et al., 2018 \\
\hline
\end{tabular}

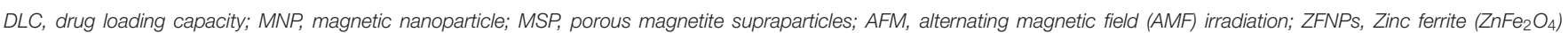

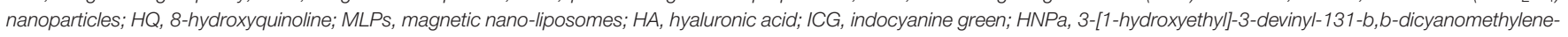
131-deoxopyropheophorbide-a.

potential suppressive effect to the intrinsic biological functions of transferrin. To overcome the drawbacks, some much advanced nanosystems have been presented (Zhang et al., 2015a,b; Ji et al., 2019; Luo et al., 2019). For example, in a recent study, Xing's group reported a system for $\mathrm{pH}$-triggered cancer chemotherapy by coating graphene oxide (GO) with both transferrin and DHA, where transferrin served as not only a cancer cell-targeting ligand but also an iron carrier (Liu et al., 2015). Most recently, Tian's group has presented a DHA encapsulated liposomal nanosystem functionalized with transferrin as tumor-targeting ligands. Elevated oxidative stress was observed specifically at the tumor site and enhanced tumor eradication was achieved by their nanosystem (Yu et al., 2020). Methemoglobin (MHb) is the most common iron-containing protein, which has also been utilized in ARTs' delivery and controlled activation through the similar mechanisms to transferring ( $\mathrm{Li}$ et al., 2017). The iron ion in both transferrin and $\mathrm{MHb}$ exists mainly as $\mathrm{Fe}^{3+}$, it will convert to $\mathrm{Fe}^{2+}$ under reductive intracellular microenvironment, thus mediating ARTs' activation (Liu et al., 2015). Other ARTs nanosystems based on $\mathrm{Fe}^{3+}$ bonded polymers may follow a similar activation mechanism as stated in Figure 1.

Polydopamine (PDA) is made from the polymerization of natural dopamine monomers, which shows the abilities to tightly coordinate with $\mathrm{Fe}^{2+}$ and $\mathrm{Fe}^{3+}$ ions. The release of these ions from polydopamine depends on the degradation of polymer structure as well as the $\mathrm{pH}$ values surrounding it. Generally, lower $\mathrm{pH}$ often leads to greater release. A recent study presented a hollow nanosphere DHA@HPDA-Fe, in which polydopamine vesicles were loaded with $\mathrm{DHA}$ and $\mathrm{Fe}^{3+}$. In vivo evidence showed that the anticancer efficacy of DHA@HPDA-Fe was 3.05 times higher compared with free DHA (Dong et al., 2019). Besides, some other biocompatible polyphenolic compounds

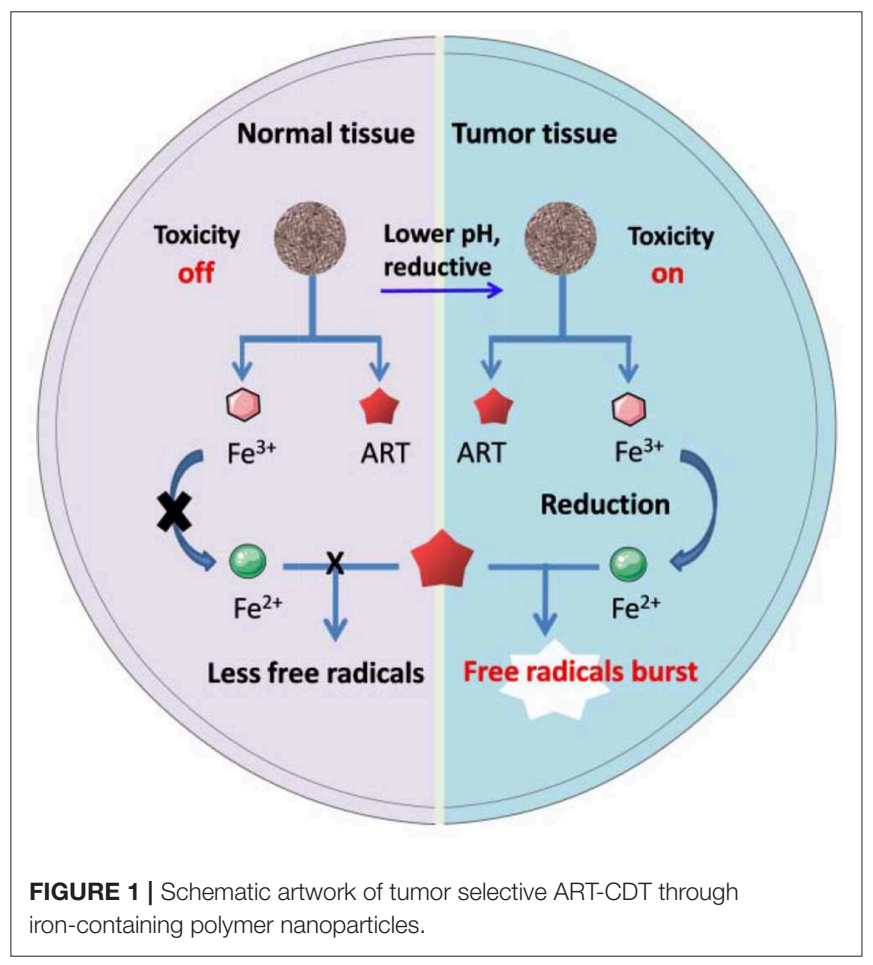

such as tannic acid have similar binding and releasing futures toward $\mathrm{Fe}^{2+}$ and $\mathrm{Fe}^{3+}$ (Kell, 2009; Du et al., 2019; He et al., 2019). These polymers could also be considered for construction of ART's nanotherapeutics, but the related research is still rare. 


\section{ARTs Nanotherapeutics Activated by Other Metal lons}

In addition to $\mathrm{Fe}^{2+}$, some other transition metal ions such as $\mathrm{Zn}^{2+}, \mathrm{Mn}^{2+}, \mathrm{Ni}^{2+}, \mathrm{Ti}^{3+}, \mathrm{Cu}^{2+}$, and $\mathrm{Co}^{2+}$ ions could also be used as catalysts to catalyze Fenton reaction (Bokare and Choi, 2014). This may greatly expand the alternatives when considering a catalyst for ARTs' activation. For instance, Chen et al. have reported a $\mathrm{Mn}^{2+}$-doped nanoparticle $\mathrm{Fe}_{3} \mathrm{O}_{4} @ \mathrm{MnSiO}_{3}$-FA for successful delivery of AS to tumors in mice models. It was found that both $\mathrm{Fe}^{2+}$ and $\mathrm{Mn}^{2+}$ would contribute to the catalyzed activation of AS. The authors further suggested that $\mathrm{Mn}^{2+}$ would be more effective to promote Fenton-like reaction and lead to more free radicals generated from AS (Chen et al., 2015). Zhou et al. presented a multifunctional nanoparticle ART-loaded mesoporous $\mathrm{NiO}(\mathrm{mNiO})$ for cancer cell targeted therapy, in which $\mathrm{Ni}^{2+}$ served as the catalyst for ART's activation. The authors found the evidence that $\mathrm{mNiO}$ can undergo degradation in acidic tumor microenvironment and release free $\mathrm{Ni}^{2+}$, which benefits the tumor selectivity over normal tissues (Liu et al., 2018). Although $\mathrm{Mn}^{2+}$ and $\mathrm{Ni}^{2+}$ doped with ARTs nanocomposites have exhibited catalytic effect in ARTs' activation, and there are still many ions alternative to choose for testing, the biocompatibility issues of such nanosystems should be greatly concerned for the purpose of real use.

\section{Nanotherapeutics With the Combination of ART-CDT and Other Therapeutic Techniques}

ARTs with peroxide bridges offer excellent radical precursors for the design of ARTs-based chemodynamic therapy (ARTCDT), which often involves the dynamic activation of ARTs and the generation of toxic free radicals (Tang et al., 2019). $\mathrm{H}_{2} \mathrm{O}_{2}$, hydroxyl radicals, and alkyl radicals are considered as the major radical species from the consequences following ART activation (Deng et al., 2019). Another radical-based therapeutic strategy is photodynamic therapy (PDT), whereby photo-mediated generation of singlet oxygen $\left({ }^{1} \mathrm{O}_{2}\right)$ is the major scientific bases for therapy. ART-CDT and PDT are all ROS involved, and the combination therapy based on both is thus attracting increasing interests (Feng et al., 2018).

More recently, Jin et al. have developed a nanosystem $\mathrm{Fe}_{3} \mathrm{O}_{4} @ \mathrm{SiO}_{2}$-ART-HNPa for cancer therapy with the combination of ART-CDT and PDT. Within their core-shell nanoparticle $\mathrm{Fe}_{3} \mathrm{O}_{4} @ \mathrm{SiO}_{2}$, ART and a porphyrin photosensitizer HNPa were encapsulated into the mesoporous structure of $\mathrm{SiO}_{2}$. In this system, ART was considered to generate ROS and alkyl radicals through $\mathrm{pH}$-mediated Fenton-like reactions. Meanwhile, ${ }^{1} \mathrm{O}_{2}$ generation from $\mathrm{HNPa}$ and molecular oxygen was mediated by NIR light $(700 \mathrm{~nm})$ excitation. Enhanced anticancer effect has been observed compared with PDT or the Fenton-like reaction alone (Qin et al., 2019). Recently, a nanoscale metal organic framework (nanoMOF) doped with $\mathrm{Fe}^{3+}$, ART, and a photosensitizer have been constructed by Tang's group for synergistic cancer therapy based on ART-CDT and PDT. In this study, $\mathrm{Fe}^{3+}$ and the photosensitizer 4,4,4,4(Porphine-5,10,15,20-tetrayl)tetrakis(benzoic acid) (TCPP) were coordinated to form the nanoMOF core structures followed by the encapsulation of DHA. To prevent non-specific DHA release, the nanoMOF was further coated with a layer of $\mathrm{CaCO}_{3}$. A $655 \mathrm{~nm}$ laser was applied for PDT during the combination therapy. Both the in vitro and in vivo results indicated synergistic therapy effect from this nanosystem, which could ablate the tumor completely on the breast cancer cell $4 \mathrm{~T} 1$-bearing mice (Wan et al., 2019).

Photothermal therapy (PTT) is a therapeutic approach of heat ablation, which uses the heat converted from pathologic tissue localized light irradiation (Vines et al., 2019). It has been found that PTT is able to improve Fenton-reaction-based therapy through enhancing the generation of ROS (Hu et al., 2017; Chen et al., 2020), thus holding the great promise to be combined with ART-CDT in cancer treatment (Wang et al., 2016b; Hu et al., 2017; Ding et al., 2018; Liu et al., 2018). Most recently, Wang et al. have presented a dual functional magnetic nanoparticle MSP@ART@P for cancer treatment based on the combination of ART-CDT and NIR laser $(785 \mathrm{~nm})$ mediated PTT. In their design, ART was firstly loaded into a magnetic iron oxide nanoparticle. A poly (aspartic acid) polymer linked with dopamine and indocyanine green (ICG) was then coated with the ART-loaded core nanoparticle. The authors have experimentally confirmed the cancer ablation effect from ART$\mathrm{CDT}$, and that the therapeutic effect could be further promoted by photothermal effect. This research offers a way to elevate cancer tissue-localized ROS generation through photosensitizer $/ \mathrm{O}_{2}$ independent manners (Ding et al., 2018).

\section{SUMMARY AND PERSPECTIVES}

The peroxide bridges existing in ARTs make them the most attractive free radical precursors for radical-based CDT. $\mathrm{Fe}^{2+}$ and $\mathrm{Fe}^{2+}$-containing complexes such as heme are considered as the major catalysts that can activate ARTs within cells through Fenton-like reactions. Based on these considerations, some iron oxide nanoparticle-based ARTs delivery and activation systems have been developed as discussed above. The activation relies on $\mathrm{Fe}^{2+}$ generation either from the direct ion release of iron oxide nanoparticles or reductive conversion of $\mathrm{Fe}^{3+}$. The controlled release and activation of ARTs could also be achieved by loading ARTs with iron-containing soft matters, which include natural iron-containing proteins such as transferrin and hemoglobin, as well as polyphenols chelated with $\mathrm{Fe}^{2+} / \mathrm{Fe}^{3+}$. The recent developments in this field have been summarized, and a few excellent cases have been discussed in details. Besides $\mathrm{Fe}^{2+}$, cancer cell-targeted release of $\mathrm{Ni}^{2+}$ and $\mathrm{Mn}^{2+}$ has also been proven effective in ARTs' activation, resulting in high antitumor activity in vitro and in vivo. In principle, some other metal ions that catalyze Fenton-like reaction can also serve as the activators for ART-CDT. However, in such kinds of design, the potential toxic issues due to the overloading of metal ions have to be carefully considered. An alternative way against the delivery of toxic metal ions is to enhance the catalytic effect of intrinsic $\mathrm{Fe}^{2+}$ by delivering a proper iron chelate into the cells. For example, heme, a protoporphyrin IX-Fe ${ }^{2+}$ complex, has been proven to 
be more effective in catalyzing activation of ARTs. The way to improve the formation of intracellular heme would be a possible strategy to enhance the anticancer activities of ARTs, which have gained evidences in some recent studies (Wang J. et al., 2017; Chen et al., 2019).

Combination of ART-CDT and other advanced therapeutic methods will be the most promising trend in the design of ARTbased nanotherapeutics. ART-CDT combined with PDT or PTT has shown synergistic effect for cancer therapy. Elevated ROS generation from ARTs is one of the major causes of synergistic effect in these combination therapies. Ultrasound irradiation mediated sonodynamic therapy (SDT) has emerged recently as a new method for cancer therapy (Canavese et al., 2018). Compared to other external stimuli such as light, ultrasound irradiation has better tissue penetrating capability. More recently, several studies have confirmed the possibilities to generate ROS in aqueous mediums through ultrasound irradiation (Gong et al., 2015; Giuntini et al., 2018). Similar to PPT, SDT is also able to

\section{REFERENCES}

Aderibigbe, A. B. (2017). Design of drug delivery systems containing artemisinin and its derivatives. Molecules 22:323. doi: 10.3390/molecules22020323

Akbarian, A., Ebtekar, M., Pakravan, N., and Hassan, Z. M. (2020). Folate receptor alpha targeted delivery of artemether to breast cancer cells with folatedecorated human serum albumin nanoparticles. Int. J. Biol. Macromol. 152, 90-101. doi: 10.1016/j.ijbiomac.2020.02.106

Bao, Y., Sherwood, J. A., and Sun, Z. (2018). Magnetic iron oxide nanoparticles as T1 contrast agents for magnetic resonance imaging. J. Mater. Chem. C. 6, 1280-1290. doi: 10.1039/C7TC05854C

Bokare, A. D., and Choi, W. (2014). Review of iron-free fenton-like systems for activating $\mathrm{H} 2 \mathrm{O} 2$ in advanced oxidation processes. J. Hazard. Mater. 275, 121-135. doi: 10.1016/j.jhazmat.2014.04.054

Canavese, G., Ancona, A., Racca, L., Canta, M., Dumontel, B., Barbaresco, F., et al. (2018). Nanoparticle-assisted ultrasound: a special focus on sonodynamic therapy against cancer. Chem. Eng. J. 340, 155-172. doi: 10.1016/j.cej.2018.01.060

Charlie-Silva, I., Fraceto, L. F., and de Melo, N. F. S. (2018). Progress in nano-drug delivery of artemisinin and its derivatives: towards to use in immunomodulatory approaches. Artif. Cells Nanomed. Biotechnol. 46, S611S620. doi: 10.1080/21691401.2018.1505739

Chen, C.-P., Chen, K., Feng, Z., Wen, X., and Sun, H. (2019). Synergistic antitumor activity of artesunate and HDAC inhibitors through elevating heme synthesis via synergistic upregulation of ALAS1 expression. Acta Pharm. Sin. B. 9, 937-951. doi: 10.1016/j.apsb.2019.05.001

Chen, D., Chen, C., Huang, C., Chen, T., and Liu, Z. (2020). Injectable hydrogel for NIR-II photo-thermal tumor therapy and dihydroartemisinin-mediated chemodynamic therapy. Front. Chem. 8:251. doi: 10.3389/fchem.2020.00251

Chen, J., Guo, Z., Wang, H.-B., Zhou, J.-J., Zhang, W.-J., and Chen, Q.-W. (2014). Multifunctional mesoporous nanoparticles as pH-responsive $\mathrm{Fe}^{2+}$ reservoirs and artemisinin vehicles for synergistic inhibition of tumor growth. Biomaterials 35, 6498-6507. doi: 10.1016/j.biomaterials.2014.04.028

Chen, J., Zhang, W., Zhang, M., Guo, Z., Wang, H., He, M., et al. (2015). $\mathrm{Mn}$ (ii) mediated degradation of artemisinin based on $\mathrm{Fe}_{3} \mathrm{O}_{4} @ \mathrm{MnSiO}_{3}$ FA nanospheres for cancer therapy in vivo. Nanoscale 7, 12542-12551. doi: $10.1039 / C 5 N R 02402 \mathrm{~A}$

Chen, Y., Lin, X., Park, H., and Greever, R. (2009). Study of artemisinin nanocapsules as anticancer drug delivery systems. Nanomedicine 5, 316-322. doi: 10.1016/j.nano.2008.12.005

De Vries, P. J., and Dien, T. K. (1996). Clinical pharmacology and therapeutic potential of artemisinin and its derivatives in the treatment of Malaria. Drugs 52, 818-836. doi: 10.2165/00003495-199652060-00004 release heat locally, thus making the potentials to accelerate the Fenton-like reaction on ARTs. The combination of ART-CDT and SDT, therefore, will be a promising option in the design of advanced ART nanotherapeutics in the future.

\section{AUTHOR CONTRIBUTIONS}

YW, ZQ, and TD drafted this manuscript. FL and QZ revised it. All authors contributed to the article and approved the submitted version.

\section{FUNDING}

We gratefully acknowledge the support by the projects of National Natural Science Foundation of China (21807018), the Department of Education of Guangdong Province (2018KQNCX047), and the Youth Scientific Research Training Project of GZUCM (2019QNPY06).

Deng, T., Hu, S., Huang, X.-A., Song, J., Xu, Q., Wang, Y., et al. (2019). A novel strategy for colorimetric detection of hydroxyl radicals based on a modified Griess test. Talanta 195, 152-157. doi: 10.1016/j.talanta.2018.11.044

Deng, T., Wang, X., Wu, S., Hu, S., Liu, W., Chen, T., et al. (2020). A new FRET probe for ratiometric fluorescence detecting mitochondria-localized drug activation and imaging endogenous hydroxyl radicals in zebrafish. Chem. Commun. 56, 4432-4435. doi: 10.1039/D0CC00382D

Ding, Y., Wan, J., Zhang, Z., Wang, F., Guo, J., and Wang, C. (2018). Localized $\mathrm{Fe}(\mathrm{II})$-induced cytotoxic reactive oxygen species generating nanosystem for enhanced anticancer therapy. ACS Appl. Mater. Interfaces. 10, 4439-4449. doi: 10.1021/acsami.7b16999

Dong, L., Wang, C., Zhen, W., Jia, X., An, S., Xu, Z., et al. (2019). Biodegradable iron-coordinated hollow polydopamine nanospheres for dihydroartemisinin delivery and selectively enhanced therapy in tumor cells. J. Mater. Chem. B 7, 6172-6180. doi: 10.1039/C9TB01397K

Du, K., Liu, Q., Liu, M., Lv, R., He, N., and Wang, Z. (2019). Encapsulation of glucose oxidase in $\mathrm{Fe}(\mathrm{III}) /$ tannic acid nanocomposites for effective tumor ablation via Fenton reaction. Nanotechnology 31:015101. doi: 10.1088/1361-6528/ab44f9

Dwivedi, A., Mazumder, A., Du Plessis, L., Du Preez, J. L., Haynes, R. K., and Du Plessis, J. (2015). In vitro anti-cancer effects of artemisone nanovesicular formulations on melanoma cells. Nanomedicine 11, 2041-2050. doi: 10.1016/j.nano.2015.07.010

Feng, G., Liu, J., Zhang, C.-J., and Liu, B. (2018). Artemisinin and AIEgen conjugate for mitochondria-targeted and image-guided chemo- and photodynamic cancer cell ablation. ACS Appl. Mater. Interfaces 10, 11546-11553. doi: 10.1021/acsami.8b01960

Gao, Z., Li, Y., You, C., Sun, K., An, P., Sun, C., et al. (2018). Iron oxide nanocarrier-mediated combination therapy of cisplatin and artemisinin for combating drug resistance through highly increased toxic reactive oxygen species generation. ACS Appl. Bio Mater. 1, 270-280. doi: 10.1021 /acsabm.8b00056

Giuntini, F., Foglietta, F., Marucco, A. M., Troia, A., Dezhkunov, N. V., Pozzoli, A., et al. (2018). Insight into ultrasound-mediated reactive oxygen species generation by various metal-porphyrin complexes. Free Radic. Biol. Med. 121, 190-201. doi: 10.1016/j.freeradbiomed.2018.05.002

Gong, C., Jiang, J., Li, D. A., and Tian, S. (2015). Ultrasonic application to boost hydroxyl radical formation during Fenton oxidation and release organic matter from sludge. Sci. Rep. 5:11419. doi: 10.1038/srep11419

Guo, S., Yao, X., Jiang, Q., Wang, K., Zhang, Y., Peng, H., et al. (2019). Dihydroartemisinin-loaded magnetic nanoparticles for enhanced chemodynamic therapy. Front. Pharmacol. 11:226. doi: $10.3389 /$ fphar. 2020.00226 
He, Z., Su, H., Shen, Y., Shi, W., Liu, X., Liu, Y., et al. (2019). Poly(norepinephrine)coated $\mathrm{FeOOH}$ nanoparticles as carriers of artemisinin for cancer photothermal-chemical combination therapy. RSC Adv. 9, 9968-9982. doi: 10.1039/C9RA01289C

Hu, P., Wu, T., Fan, W., Chen, L., Liu, Y., Ni, D., et al. (2017). Near infrared-assisted Fenton reaction for tumor-specific and mitochondrial DNA-targeted photochemotherapy. Biomaterials 141, 86-95. doi: 10.1016/j.biomaterials.2017.06.035

Jabbarzadegan, M., Rajayi, H., Mofazzal Jahromi, M. A., Yeganeh, H., Yousefi, M., Muhammad Hassan, Z., et al. (2017). Application of arteether-loaded polyurethane nanomicelles to induce immune response in breast cancer model. Artif. Cells Nanomed. Biotechnol. 45, 808-816. doi: 10.1080/21691401.2016.1178131

Ji, P., Huang, H., Yuan, S., Wang, L., Wang, S., Chen, Y., et al. (2019). ROSmediated apoptosis and anticancer effect achieved by artesunate and auxiliary $\mathrm{Fe}(\mathrm{II})$ released from ferriferous oxide-containing recombinant apoferritin. $A d v$. Healthc. Mater. 8:1900911. doi: 10.1002/adhm.201900911

Kalepu, S., and Nekkanti, V. (2015). Insoluble drug delivery strategies: review of recent advances and business prospects. Acta Pharmaceutica Sinica B. 5, 442-453. doi: 10.1016/j.apsb.2015.07.003

Kell, D. B. (2009). Iron behaving badly: inappropriate iron chelation as a major contributor to the aetiology of vascular and other progressive inflammatory and degenerative diseases. BMC Med. Genomics 2:2. doi: 10.1186/17558794-2-2

Krishna, S., Bustamante, L., Haynes, R. K., and Staines, H. M. (2008). Artemisinins: their growing importance in medicine. Trends Pharmacol. Sci. 29, 520-527. doi: 10.1016/j.tips.2008.07.004

Lai, H., Sasaki, T., Singh, N. P., and Messay, A. (2005). Effects of artemisinin-tagged holotransferrin on cancer cells. Life Sci. 76, 1267-1279. doi: 10.1016/j.lfs.2004.08.020

Li, H., Chen, Y., Chen, T., Han, H., Tong, H., Jin, Q., et al. (2017). Methemoglobin as a redox-responsive nanocarrier to trigger the in situ anticancer ability of artemisinin. NPG Asia Mater. 9:e423. doi: 10.1038/am.2017.150

Li, H., Li, X., Shi, X., Li, Z., and Sun, Y. (2019). Effects of magnetic dihydroartemisinin nano-liposome in inhibiting the proliferation of head and neck squamous cell carcinomas. Phytomedicine 56, 215-228. doi: 10.1016/j.phymed.2018.11.007

Li, Y. (2012). Qinghaosu (artemisinin): chemistry and pharmacology. Acta Pharmacol. Sin. 33, 1141-1146. doi: 10.1038/aps.2012.104

Liechty, W. B., Kryscio, D. R., Slaughter, B. V., and Peppas, N. A. (2010). Polymers for drug delivery systems. Annu. Rev. Chem. Biomol. Eng. 1, 149-173. doi: 10.1146/annurev-chembioeng-073009-100847

Liu, L., Liu, Y., Ma, L., Mao, F., Jiang, A., Liu, D., et al. (2018). Artemisininloaded mesoporous nanoplatform for $\mathrm{pH}$-responsive radical generation synergistic tumor theranostics. ACS Appl. Mater. Interfaces 10, 6155-6167. doi: 10.1021 /acsami.7b18320

Liu, L., Wei, Y., Zhai, S., Chen, Q., and Xing, D. (2015). Dihydroartemisinin and transferrin dual-dressed nano-graphene oxide for a $\mathrm{pH}$-triggered chemotherapy. Biomaterials 62, 35-46. doi: 10.1016/j.biomaterials.2015. 05.036

Luo, Y., Sun, X., Huang, L., Yan, J., Yu, B.-Y., and Tian, J. (2019). Artemisininbased smart nanomedicines with self-supply of ferrous ion to enhance oxidative stress for specific and efficient cancer treatment. ACS Appl. Mater. Interfaces 11, 29490-29497. doi: 10.1021/acsami.9b07390

Malmsten, M. (2006). Soft drug delivery systems. Soft Matter. 2, 760-769. doi: $10.1039 / \mathrm{B} 608348 \mathrm{~J}$

Mangrio, F. A., Dwivedi, P., Han, S., Zhao, G., Gao, D., Si, T., et al. (2017). Characteristics of artemether-loaded poly(lactic-co-glycolic) acid microparticles fabricated by coaxial electrospray: validation of enhanced encapsulation efficiency and bioavailability. Mol. Pharm. 14, 4725-4733. doi: 10.1021/acs.molpharmaceut.7b00862

Manjili, H. K., Malvandi, H., Mousavi, M. S., Attari, E., and Danafar, H. (2018). In vitro and in vivo delivery of artemisinin loaded PCL-PEG-PCL micelles and its pharmacokinetic study. Artif. Cells Nanomed. Biotechnol. 46, 926-936. doi: 10.1080/21691401.2017.1347880

Mcatee, C. O., Barycki, J. J., and Simpson, M. A. (2014). Emerging roles for hyaluronidase in cancer metastasis and therapy. Adv. Cancer Res. 123, 1-34. doi: 10.1016/B978-0-12-800092-2.00001-0
Nakase, I., Lai, H., Singh, N. P., and Sasaki, T. (2008). Anticancer properties of artemisinin derivatives and their targeted delivery by transferrin conjugation. Int. J. Pharm. 354, 28-33. doi: 10.1016/j.ijpharm.2007.09.003

O'neill, P. M., Barton, V. E., and Ward, S. A. (2010). The molecular mechanism of action of artemisinin-the debate continues. Molecules 15, 1705-1721. doi: 10.3390/molecules 15031705

Pan, U. N., Sanpui, P., Paul, A., and Chattopadhyay, A. (2018). Synergistic anticancer potential of artemisinin when loaded with 8-hydroxyquinolinesurface complexed-zinc ferrite magnetofluorescent nanoparticles and albumin composite. ACS Appl. Bio Mater. 1, 1229-1235. doi: 10.1021/acsabm.8b00358

Patra, J. K., Das, G., Fraceto, L. F., Campos, E. V. R., Rodriguez-Torres, M. D. P., Acosta-Torres, L. S., et al. (2018). Nano based drug delivery systems: recent developments and future prospects. J. Nanobiotechnology 16:71. doi: 10.1186/s12951-018-0392-8

Pfeifhofer-Obermair, C., Tymoszuk, P., Petzer, V., Weiss, G., and Nairz, M. (2018). Iron in the tumor microenvironment-connecting the dots. Front. Oncol. 8:549. doi: $10.3389 /$ fonc.2018.00549

Qin, X., Zhang, H., Wang, Z., and Jin, Y. (2019). $\mathrm{Fe}_{3} \mathrm{O}_{4} @ \mathrm{SiO}_{2}$ mesoporous spheres as $\mathrm{Fe}$ (ii) donors loaded with artemisinin and a photosensitizer to alleviate tumor hypoxia in PDT for enhanced anticancer therapy. New J. Chem. 43, 8761-8773. doi: 10.1039/C9NJ00974D

Tang, Z., Liu, Y., He, M., and Bu, W. (2019). Chemodynamic therapy: tumour microenvironment-mediated fenton and fenton-like reactions. Angew. Chem. Int. Edit. 58, 946-956. doi: 10.1002/anie.201805664

Tran, T., Nguyen, T., Nguyen, H., Nguyen, H. T., Kim, J., Yong, C., et al. (2016). Targeted and controlled drug delivery system loading artersunate for effective chemotherapy on CD44 overexpressing cancer cells. Arch. Pharm. Res. 39, 687-694. doi: 10.1007/s12272-016-0738-4

Vines, J. B., Yoon, J. H., Ryu, N. E., Lim, D. J., and Park, H. (2019). Gold nanoparticles for photothermal cancer therapy. Front. Chem. 7:167. doi: 10.3389/fchem.2019.00167

Wan, X., Zhong, H., Pan, W., Li, Y., Chen, Y., Li, N., et al. (2019). Programmed release of dihydroartemisinin for synergistic cancer therapy using a $\mathrm{CaCO}_{3}$ mineralized metal-organic framework. Angew. Chem. Int. Edit. 131, 14272-14277. doi: 10.1002/ange.201907388

Wang, D., Zhou, J., Chen, R., Shi, R., Wang, C., Lu, J., et al. (2017). Core-shell metal-organic frameworks as $\mathrm{Fe}^{2+}$ suppliers for $\mathrm{Fe}^{2+}$-mediated cancer therapy under multimodality imaging. Chem. Mater. 29, 3477-3489. doi: 10.1021/acs.chemmater.6b05215

Wang, D., Zhou, J., Chen, R., Shi, R., Xia, G., Zhou, S., et al. (2016a). Magnetically guided delivery of DHA and Fe ions for enhanced cancer therapy based on $\mathrm{pH}$ responsive degradation of DHA-loaded $\mathrm{Fe}_{3} \mathrm{O}_{4} @ \mathrm{C} @ M I L-100(\mathrm{Fe})$ nanoparticles. Biomaterials 107, 88-101. doi: 10.1016/j.biomaterials.2016.08.039

Wang, D., Zhou, J., Chen, R., Shi, R., Zhao, G., Xia, G., et al. (2016b). Controllable synthesis of dual-MOFs nanostructures for $\mathrm{pH}$-responsive artemisinin delivery, magnetic resonance and optical dual-model imagingguided chemo/photothermal combinational cancer therapy. Biomaterials 100, 27-40. doi: 10.1016/j.biomaterials.2016.05.027

Wang, J., Zhang, C. J., Chia, W. N., Loh, C. C., Li, Z., Lee, Y. M., et al. (2015). Haemactivated promiscuous targeting of artemisinin in Plasmodium falciparum. Nat Commun. 6:10111. doi: 10.1038/ncomms10111

Wang, J., Zhang, J., Shi, Y., Xu, C., Zhang, C., Wong, Y. K., et al. (2017). Mechanistic investigation of the specific anticancer property of artemisinin and its combination with aminolevulinic acid for enhanced anticolorectal cancer activity. ACS Cent. Sci. 3, 743-750. doi: 10.1021/acscentsci.7b00156

Wong, Y. K., Xu, C., Kalesh, K. A., He, Y., Lin, Q., Wong, W. S. F., et al. (2017). Artemisinin as an anticancer drug: Recent advances in target profiling and mechanisms of action. Med. Res. Rev. 37, 1492-1517. doi: 10.1002/med.21446

Xiao, Y. S., Huang, W., Zhu, D. M., Wang, Q. X., Chen, B. Y., Liu, Z. S., et al. (2020). Cancer cell membrane-camouflaged MOF nanoparticles for a potent dihydroartemisinin-based hepatocellular carcinoma therapy. RSC Adv. 10, 7194-7205. doi: 10.1039/C9RA09233A

Yu, X.-A., Lu, M., Luo, Y., Hu, Y., Zhang, Y., Xu, Z., et al. (2020). A cancer-specific activatable theranostic nanodrug for enhanced therapeutic efficacy via amplification of oxidative stress. Theranostics 10, 371-383. doi: 10.7150/thno.39412

Zhang, H., Chen, Q., Zhang, X., Zhu, X., Chen, J., Zhang, H., et al. (2016). An intelligent and tumor-responsive $\mathrm{Fe}^{2+}$ donor and $\mathrm{Fe}^{2+}$-dependent 
drugs cotransport system. ACS Appl. Mater. Interfaces 8, 33484-33498. doi: 10.1021/acsami.6b11839

Zhang, H., Hou, L., Jiao, X., Ji, Y., Zhu, X., and Zhang, Z. (2015a). Transferrin-mediated fullerenes nanoparticles as Fe2+-dependent drug vehicles for synergistic anti-tumor efficacy. Biomaterials 37, 353-366. doi: 10.1016/j.biomaterials.2014.10.031

Zhang, H., Ji, Y., Chen, Q., Jiao, X., Hou, L., Zhu, X., et al. (2015b). Enhancement of cytotoxicity of artemisinin toward cancer cells by transferrinmediated carbon nanotubes nanoparticles. J. Drug Target 23, 552-567. doi: 10.3109/1061186X.2015.1016437

Zhang, H., Zhang, H., Zhu, X., Zhang, X., Chen, Q., Chen, J., et al. (2017). Visible-light-sensitive titanium dioxide nanoplatform for tumor-responsive Fe2+ liberating and artemisinin delivery. Oncotarget 8, 58738-58753. doi: 10.18632/oncotarget.17639

Zhang, Y., Xu, G., Zhang, S., Wang, D., Saravana Prabha, P., and Zuo, Z. (2018). Antitumor research on artemisinin and its bioactive derivatives. Nat. Products Bioprospect. 8, 303-319. doi: 10.1007/s13659-018-0162-1
Zhao, P., Tang, Z., Chen, X., He, Z., He, X., Zhang, M., et al. (2019). Ferrous-cysteine-phosphotungstate nanoagent with neutral $\mathrm{pH}$ fenton reaction activity for enhanced cancer chemodynamic therapy. Mater. Horiz. 6, 369-374. doi: 10.1039/C8MH0 $1176 \mathrm{~A}$

Conflict of Interest: The authors declare that the research was conducted in the absence of any commercial or financial relationships that could be construed as a potential conflict of interest.

Copyright (c) $2020 \mathrm{Wu}$, Zeng, Qi, Deng and Liu. This is an open-access article distributed under the terms of the Creative Commons Attribution License (CC BY). The use, distribution or reproduction in other forums is permitted, provided the original author(s) and the copyright owner(s) are credited and that the original publication in this journal is cited, in accordance with accepted academic practice. No use, distribution or reproduction is permitted which does not comply with these terms. 